\title{
Design and Control of a New Double-Stator Cup-Rotor Permanent-Magnet Machine for Wind Power Generation
}

\author{
Shuangxia Niu ${ }^{1}$, K. T. Chau ${ }^{1}$, J. Z. Jiang ${ }^{2}$, and Chunhua Liu ${ }^{1}$ \\ ${ }^{1}$ Department of Electrical and Electronic Engineering, The University of Hong Kong, Hong Kong, China \\ ${ }^{2}$ Department of Automation, Shanghai University, Shanghai, China
}

In this paper, a new double-stator cup-rotor permanent-magnet machine is proposed and implemented for wind power generation. The design of unique double-stator configuration can improve the power density for easy installation, while the control of its winding connections can provide a constant output voltage over a wide range of wind speeds. The circuit-field-torque coupled time-stepping finite element method is utilized to analyze the proposed machine. Both analysis and experimental results are given to confirm the validity of the proposed machine.

Index Terms-Cup rotor, double stator, finite element method, permanent-magnet machine, wind power.

\section{INTRODUCTION}

B ECAUSE of high efficiency and high power density, permanent-magnet (PM) machines have attracted considerable attention for wind power generation [1]. However, in the absence of flux control, they usually produce a highly fluctuating output voltage under varying wind speeds. Recently, the concept of double-stator cup-rotor PM (DSCR-PM) machine has been introduced to perform flux control [2]. However, it needs mechanical shifting of the two stators, which is impractical for online control.

The purpose of this paper is to propose an electrical means to perform flux control of the DSCR-PM machine so that it will retain the original high power density while eliminating the complicated mechanism for mechanical shifting. The flux control will be realized by online changing the connections of the two sets of 3-phase windings based on a matrix converter. Thus, the proposed machine will maintain the generated output voltage constant over a wide range of wind speeds. Since the machine configuration is unique, the circuit-field-torque coupled time-stepping finite-element method (CFT-TS-FEM) [3] will be employed to analyze both the steady-state and dynamic characteristics of the proposed machine.

\section{MAChine Configuration}

The configuration of the proposed DSCR-PM machine is shown in Fig. 1, in which there are two stators each with 22 poles and 24 slots, and a cup-shaped rotor with PMs mounted on both inner and outer surfaces. Each stator adopts a 3-phase single-layer winding structure, in which the coil-pitch is equal to the slot-pitch. There are some distinct advantages. 1) Due to the multipole structure, the total length of the magnetic path is reduced, hence saving the iron yoke material and resulting in higher power density. 2) Because of the coil-pitch equal to the slot-pitch, the end winding is shorter, hence saving the copper material and further improving the power density. 3) Since the cup-rotor structure can effectively shorten the magnetic path length, it can further reduce the iron yoke material and hence improve the power density. 4) As there are two sets of

Digital Object Identifier 10.1109/TMAG.2007.893713

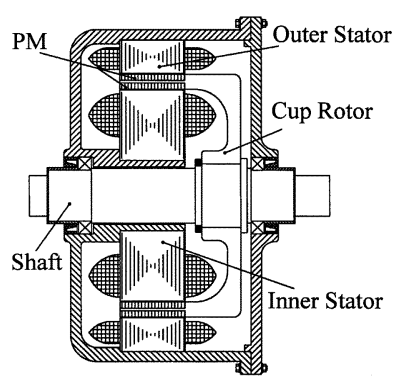

(a)

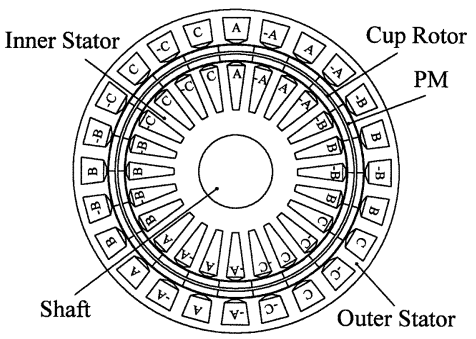

(b)
Fig. 1. Proposed machine configuration. (a) Front view. (b) Side view.

3-phase windings, the six winding terminals can be connected in different ways to achieve effective flux control, including both flux strengthening and weakening effects.

\section{PRINCIPLE OF OPERATION}

The machine is so unique that the two sets of 3-phase stator windings can be flexibly connected. Hence, the composite vector of the two 3-phase voltages can be online controlled in such a way that the generated output voltage is kept constant over a wide range of wind speeds. When there is a spatial angle of $20^{\circ}$ between the two stators, it yields six possible ways to connect the two sets of 3-phase windings as shown in Fig. 2. When the machine speed $\omega$ is below the base speed $\omega_{b}$, the same phases (for instance, $E_{A}$ and $E_{a}$ ) are connected in series to form $E_{1}$, so-called the Mode 1 shown in Fig. 2(a). Between $\omega_{b}$ and $1.2 \omega_{b}$, the adjacent anti-phases are connected in series to form $E_{2}$, the Mode 2 in Fig. 2(b). Similarly, between $1.2 \omega_{b}$ and $1.5 \omega_{b}, E_{3}$ is formed as the Mode 3 in Fig. 2(c). Then, between $1.5 \omega_{b}$ and $2 \omega_{b}$, the adjacent phases are connected in series to form $E_{4}$ as the Mode 4 in Fig. 2(d). Similarly, between $2 \omega_{b}$ and $3 \omega_{b}, E_{5}$ is formed as the Mode 5 in Fig. 2(e). Finally, between $3 \omega_{b}$ and $6 \omega_{b}$, the same anti-phases are connected in series to form $E_{6}$ as the Mode 6 in Fig. 2(f). Based on the vector diagrams, it can be found that $E_{1} \approx 6 E_{6}, E_{2} \approx 5 E_{6}, E_{3} \approx 4 E_{6}, E_{4} \approx 3 E_{6}$ and $E_{5} \approx 2 E_{6}$, indicating that the generated EMF can be discretely tuned in terms of $E_{6}$. For further fine tuning or with speed beyond $6 \omega_{b}$, the conventional flux weakening control can be employed to adjust the output voltage. 


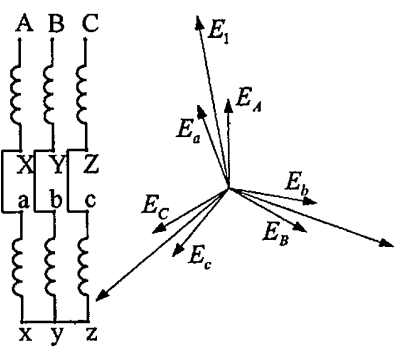

(a)

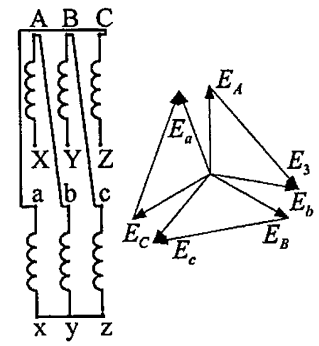

(c)

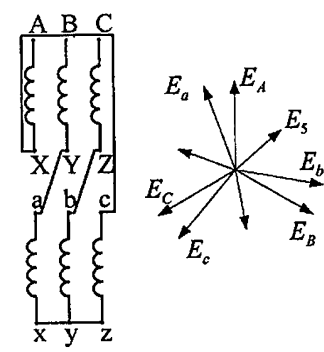

(e)

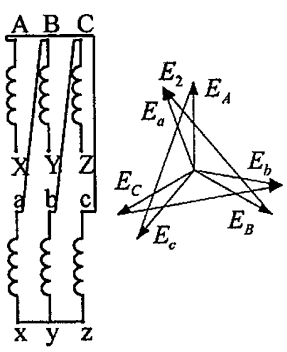

(b)
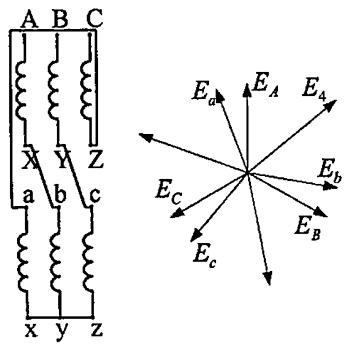

(d)
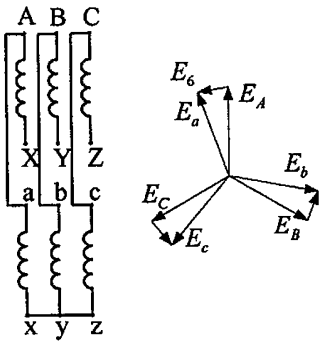

(f)
Fig. 2. Different winding connections and vector diagrams. (a) Mode 1. (b) Mode 2. (c) Mode 3. (d) Mode 4. (e) Mode 5. (f) Mode 6.

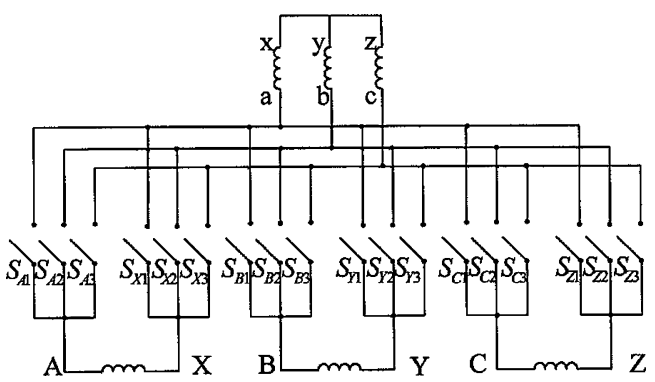

Fig. 3. Control of winding connections using matrix converter.

TABLE I

SWITCHING COMBINATIONS IN DIFFERENT MODES

\begin{tabular}{c|cccccc}
\hline Mode & 1 & 2 & 3 & 4 & 5 & 6 \\
\hline \multirow{2}{*}{ Turn-on } & $S_{X 1}$ & $S_{A 3}$ & $S_{A 2}$ & $S_{X 2}$ & $S_{X 3}$ & $S_{A 1}$ \\
switching & $S_{Y 2}$ & $S_{B 1}$ & $S_{B 3}$ & $S_{Y 3}$ & $S_{Y 1}$ & $S_{B 2}$ \\
& $S_{Z 3}$ & $S_{C 2}$ & $S_{C 1}$ & $S_{Z 1}$ & $S_{Z 2}$ & $S_{C 3}$ \\
\hline
\end{tabular}

\section{CONTROL Circuit}

As shown in Fig. 3, a matrix converter is newly developed for the proposed DSCR-PM machine. This matrix converter is composed of a matrix of power switches, which takes the definite

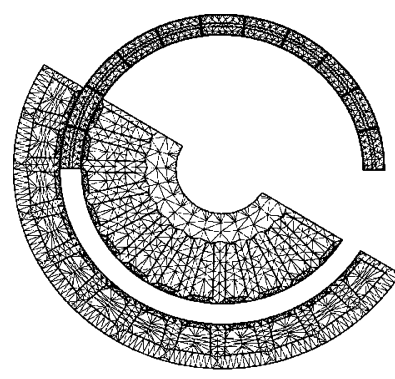

(a)

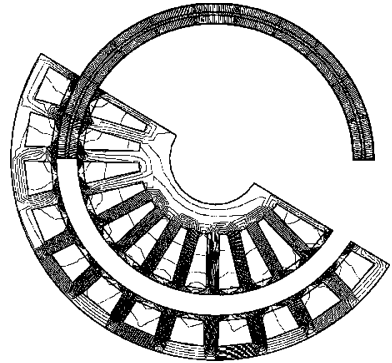

(b)
Fig. 4. CFT-TS-FEM analysis. (a) Mesh. (b) Magnetic field distribution.

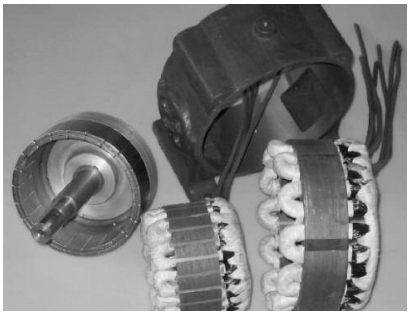

Fig. 5. Machine prototype.

advantage that it can provide versatile control and regulation of power flow. It is first used for controlling the winding connections of the proposed machine. The corresponding switching combinations are tabulated in Table I. It can readily be extended to perform other sophisticated power flow control.

\section{FIELD ANALYSIS}

The two-dimensional CFT-TS-FEM [3] is employed to analyze the characteristics of the proposed machine. Based on common nomenclature of symbols, the governing equation for electromagnetic field analysis is given by

$\frac{\partial}{\partial x}\left(v \frac{\partial A}{\partial x}\right)+\frac{\partial}{\partial y}\left(v \frac{\partial A}{\partial y}\right)=-J+\sigma \frac{\partial A}{\partial t}-v \frac{\partial B_{\mathrm{ry}}}{\partial x}+v \frac{\partial B_{\mathrm{rx}}}{\partial y}$.

The circuit equation of the machine is given by

$$
\left(R+R_{l}\right) i+\left(L_{e}+L_{l}\right) \frac{d i}{d t}=\frac{l}{S} \iint_{\Omega} \frac{\partial A}{\partial t} d \Omega .
$$

The motion equation is given by

$$
J_{m} \frac{d \omega}{d t}=T_{e}-T_{l}-B_{m} \omega .
$$

After coupling (1) to (3), the time stepping discretization can be performed to calculate both steady-state and dynamic characteristics. During the rotation of the rotor mesh, the sliding surface technique is employed to avoid reshaping the mesh. The finite element mesh and the corresponding magnetic field distribution at rated load are shown in Fig. 4.

\section{RESULTS AND VERIFICATION}

The proposed DSCR-PM machine is prototyped as shown in Fig. 5. Table II gives a comparison of the proposed machine and a surface-PM machine with the same size, electric loading (18400 A-conductors) and magnetic loading $(0.8 \mathrm{~T})$. At the same rated speed $(300 \mathrm{rpm})$, their power densities are 
TABLE II

COMPARISON OF MACHINE POWER DENSITIES

\begin{tabular}{l|ll}
\hline & DSCR-PM & Surface-PM \\
\hline Outside diameter $(\mathrm{mm})$ & 245 & 245 \\
Stack length $(\mathrm{mm})$ & 50 & 50 \\
Slot area $\left(\mathrm{mm}^{2}\right)$ & 600 & 600 \\
Rated power $(\mathrm{kW})$ & 1.6 & 1.25 \\
Power density $(\mathrm{kW} / \mathrm{kg})$ & 102.7 & 88.8 \\
Power density $\left(\mathrm{kW} / \mathrm{m}^{3}\right)$ & 678.8 & 530.3 \\
\hline
\end{tabular}
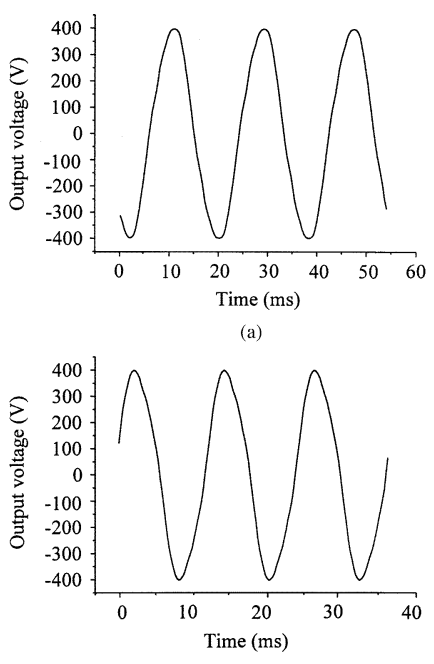

(c)

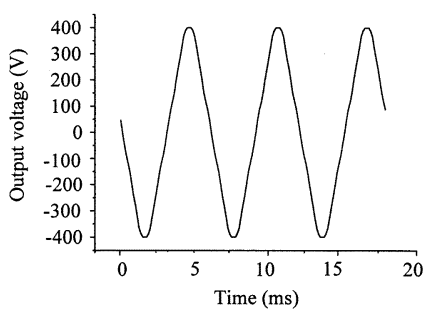

(e)

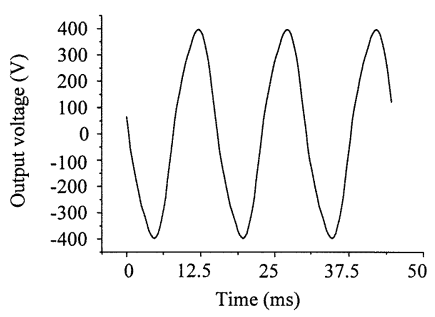

(b)
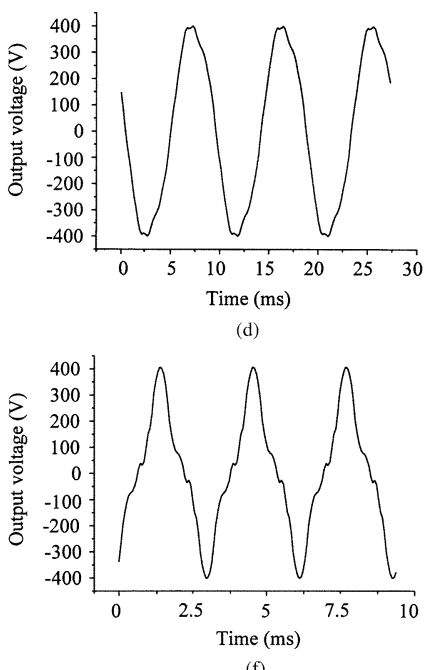

(f)
Fig. 6. Simulated output voltages in different modes. (a) $300 \mathrm{rpm}$. (b) $360 \mathrm{rpm}$. (c) $450 \mathrm{rpm}$. (d) $600 \mathrm{rpm}$. (e) $900 \mathrm{rpm}$. (f) $1800 \mathrm{rpm}$.

calculated based on the active materials. It can be found that the proposed machine offers higher gravimetric and volumetric power densities by $13.5 \%$ and $21.9 \%$, respectively. To illustrate the key merit of the proposed machine, the generated output voltage waveforms in the six modes of operation (covering a very wide range of wind speeds) are simulated as shown in Fig. 6. The measured waveforms under the same conditions are shown in Fig. 7. The agreement is very good.

To measure the power handling capability, the winding connection is kept in series. As shown in Fig. 8(a), the output power can achieve up to $10 \mathrm{~kW}$ at $1800 \mathrm{rpm}$. Also, as shown in Fig. 8(b), the efficiency can be maintained at high values over a wide range of load currents and rotor speeds.

\section{CONCLUSION}

In this paper, a new DSCR-PM wind-power generator has been proposed and implemented. It offers the advantages that the unique configuration can improve the power density for easy installation, and the versatile control of winding connections can provide a constant output voltage over a wide range of wind

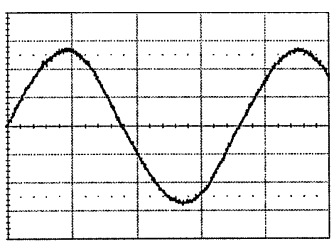

(a)

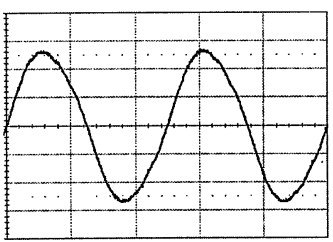

(c)

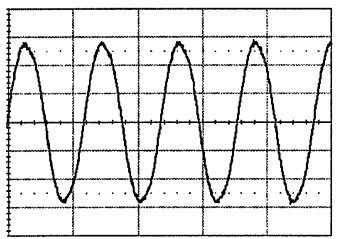

(e)

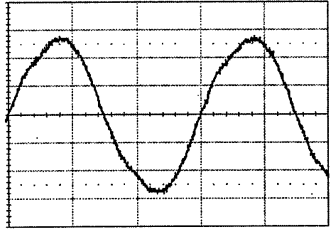

(b)

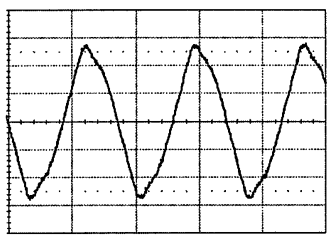

(d)

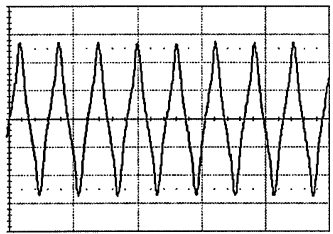

(f)
Fig. 7. Measured output voltages in different modes (146 V/div, $5 \mathrm{~ms} / \mathrm{div})$. (a) $300 \mathrm{rpm}$. (b) $360 \mathrm{rpm}$. (c) $450 \mathrm{rpm}$. (d) $600 \mathrm{rpm}$. (e) $900 \mathrm{rpm}$. (f) $1800 \mathrm{rpm}$.
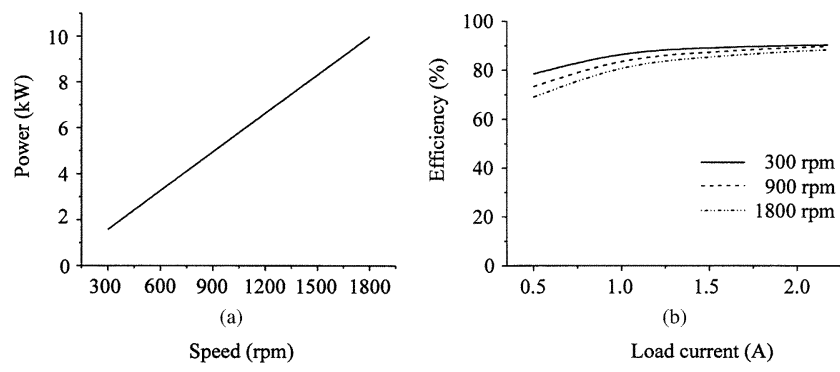

Fig. 8. Measured load characteristics in Mode 1. (a) Power. (b) Efficiency.

speeds. The analysis results obtained from the CFT-TS-FEM have been experimentally verified.

\section{ACKNOWLEDGMENT}

This work was supported and funded by a grant (Project No. HKU 7111/05E) from the Research Grants Council, Hong Kong Special Administrative Region, China.

\section{REFERENCES}

[1] Y. Fan, K. T. Chau, and M. Cheng, "A new three-phase doubly salient permanent magnet machine for wind power generation," IEEE Trans. Ind. Appl., vol. 42, no. 1, pp. 53-60, Jan./Feb. 2006.

[2] F. Chai, S. Cui, and S. Cheng, "Performance analysis of double-stator starter generator for the hybrid electric vehicle," IEEE Trans. Magn., vol. 41, no. 1, pp. 484-487, Jan. 2005.

[3] Y. Wang, K. T. Chau, C. C. Chan, and J. Z. Jiang, "Transient analysis of a new outer-rotor permanent-magnet brushless dc drive using circuitfield-torque time-stepping finite element method," IEEE Trans. Magn., vol. 38, no. 2, pp. 1297-1300, Mar. 2002.

Manuscript received October 31, 2006 (e-mail: sxniu@eee.hku.hk). 